www.jmscr.igmpublication.org

Index Copernicus Value: 79.54

ISSN (e)-2347-176x ISSN (p) 2455-0450

crossref DOI: https://dx.doi.org/10.18535/jmscr/v7i6.51

Journal Of Medical Science And Clinical Research

IGM Publication

An Official Publication of IGM Publication

\title{
Hydrocele: Side Incidence and Age Group Affected
}

\author{
Author
}

\section{Dr Gurmeet Singh Sarla}

Senior Advisor Surgery, Military Hospital Devlali, Devlali Cantt, Nasik, Maharashtra. Pin 422401

\begin{abstract}
Background: Hydrocele is collection of fluid along the path of testicular descent which usually presents as a painless, cystic scrotal mass leading to an increase in the volume of the scrotal contents.

Aim: The aim of this study is to analyse the side incidence and age groups affected in hydrocele.

Materials and Methods: A total of 110 patients who were diagnosed clinically and sonologically as having long standing hydrocele of 6 months and more were included in the study and were offered surgery in the form of eversion of sac. Patients with acute onset hydrocele/haematocele and associated with trauma were not included in the study. None of these patients on preoperative ultrasound or on surgical exploration was diagnosed with a more serious underlying pathology.

Results: Out of 110 patients who underwent eversion of sac for hydrocele, 60 (54.54\%) patients had Right sided hydrocele and $46(41.81 \%)$ patients had Left sided hydrocele. 4 (3.63\%) patients had bilateral hydrocele. The most common age group affected was the age bracket of 31-40 years which comprised of 38 (34.54\%) patients, followed by age group between 21-30 years, 41-50 years and 51-60 years each of the group affecting 20 (18.18\%) patients.

Conclusion: Right sided hydrocele is more common as compared to left sided hydrocele. This study showed that 60 (54.54\%) patients had Right sided hydrocele as compared to 46 (41.81\%) patients who had Left sided hydrocele. The age group of 31-40 years was the most commonly affected age group affected which consisted of 34.54\% of patients. This was followed closely by age group of 21-30 years, 41-50 years and 51-60 years which affected 18.18\% patients each.

Keywords: Hydrocele, side incidence, age group affected.
\end{abstract}

\section{Introduction}

A hydrocele is a fluid collection that may occur anywhere along the path of testicular descent and usually presents as a painless, cystic scrotal mass leading to an increase in the volume of the scrotal contents. Depending on the volume of fluid, hydrocele can be disfiguring and even incapacitating. The hydrocele may be communicating, with fluid of peritoneal origin, or non-communicating, where fluid arises from the mesothelial lining of the tunica vaginalis. Physical examination reveals a smooth and non tender scrotal mass that is clear upon transillumination. hydroceles can be associated with testicular neoplasms in post pubertal males, testicular examination should be performed. If the size of the hydrocele precludes adequate testicular examination, scrotal ultrasonography is advised. Chronic hydrocele has multiple etiologies, but irrespective of the cause, surgery is the standard form of treatment and this can be done using different surgical techniques. 


\section{Aim}

The aim of this study is to analyse the side incidence and age groups affected in hydrocele.

\section{Materials and Methods}

A total of 110 patients who reported to the surgical out-patient department over a period of 3 years from May 2016 to May 2019 and were diagnosed clinically and sonologically as having hydrocele of long standing duration of 6 months and more were included in the study. All the patients were offered surgery in the form of Eversion of sac. Transillumination was used as an important screening component of physical examination of patients presenting with scrotal masses which required a bright focal light source in a dark room.

Patients with acute onset hydrocele/haematocele and associated with trauma were not included in the study.

None of these patients on preoperative ultrasound or on surgical exploration was diagnosed with a more serious underlying pathology.

\section{Results}

Out of 110 patients who underwent eversion of sac for hydrocele, 60 (54.54\%) patients had Right sided hydrocele and $46(41.81 \%)$ patients had Left sided hydrocele. $4(3.63 \%)$ patients had bilateral hydrocele.

Chart 1: Side incidence of Hydrocele

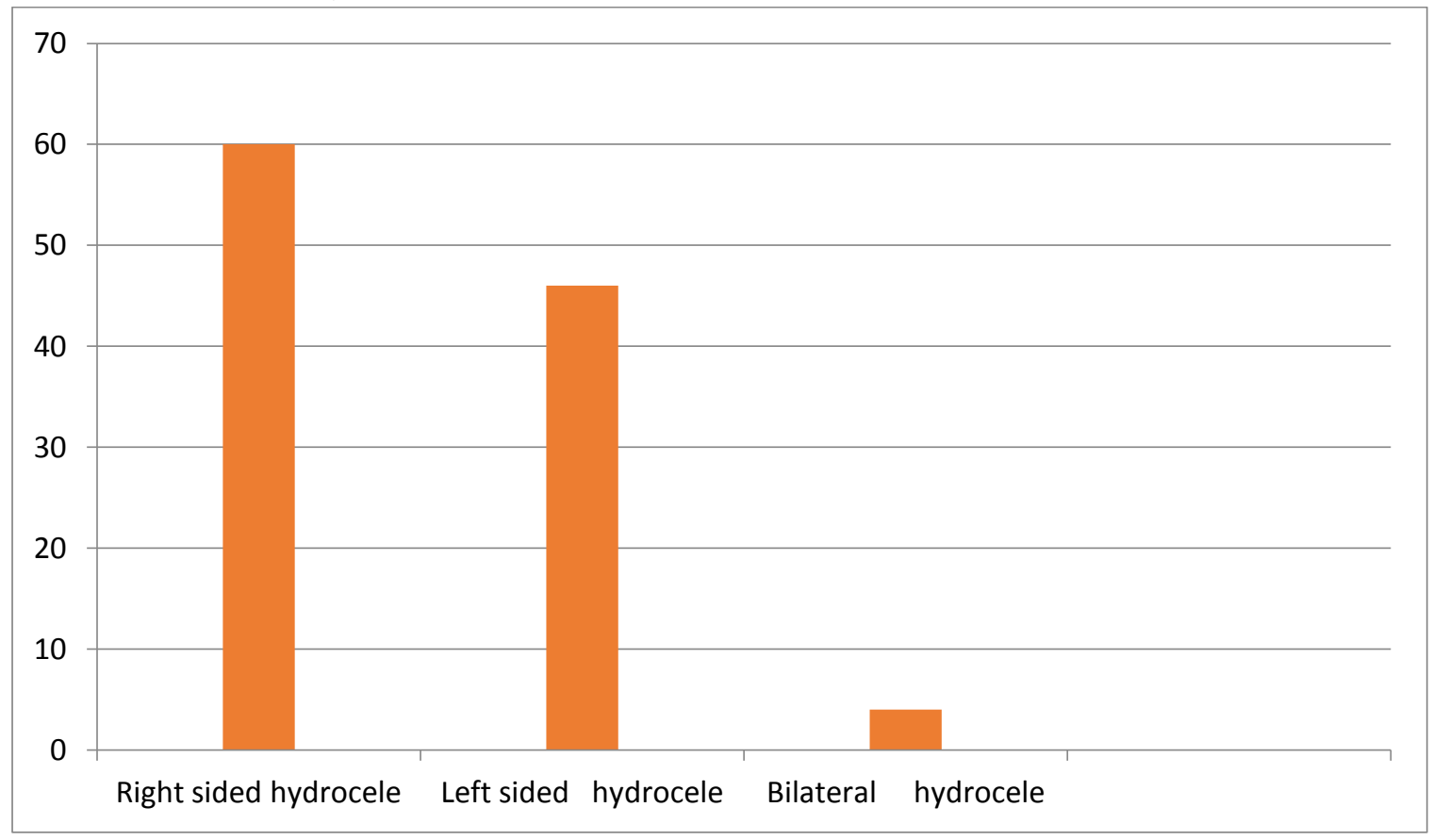

The most common age group affected was the age bracket of 31-40 years which comprised of 38 (34.54\%) patients, followed by age group between 21-30 years, 41-50 years and 51- 60 years each of the group affecting $20(18.18 \%)$ patients.

Table 1: Age group affected

\begin{tabular}{|l|c|c|}
\hline Age group & Number of patients & Percentage \\
\hline 11-20 years & 4 & $3.63 \%$ \\
\hline 21-30 years & 20 & $18.18 \%$ \\
\hline 31-40 years & 38 & $34.54 \%$ \\
\hline 41-50 years & 8 & $7.27 \%$ \\
\hline 51-60 years & 20 & $18.18 \%$ \\
\hline 61-70 years & 20 & $18.18 \%$ \\
\hline
\end{tabular}

\section{Discussion}

Hydrocele is defined as an abnormal collection of serous fluid in the potential space between the parietal and visceral layers of the tunica vaginalis. The pathogenesis of idiopathic hydrocele is thought to be an imbalance in the normal process of fluid production and reabsorption. The diagnosis is usually clinical. Scrotal ultrasonography is mandatory in non palpable testicles to rule out an associated testicular mass requiring inguinal exploration. 
Adult hydrocele is a very common urological disease in most of the sub-Saharan African countries, with a reported incidence of up to 20$28 \%$ in some lymphatic filariasis endemic communities. ${ }^{1}$ Diagnosis is usually clinical. Scrotal ultrasound is recommended in adult men with hydrocele as part of the diagnostic work$u^{2}$ to rule out testicular cancer and testicular torsion.

The most definitive treatment for hydrocele is surgery; however, many symptomatic sub-Saharan African patients live with this condition for years without surgery often due to financial constraints and lack of access to medical care. This situation unfortunately is common to most developing countries. $^{3}$

The distribution of the incidence of hydrocele in this study showed its peak in the age group between 31-40 years as opposed to two peaks at ages 20-29 years and later 50 years and above, with a steady increase in incidence after the age of 50 years in another study by Okorie $\mathrm{CO}$ et al. ${ }^{4}$ Incidence of bilateral hydrocele seemed to be very low between 41- 50 years of age similar to the study by Okorie CO et al. ${ }^{4}$ Unilateral hydrocele seemed to occur more frequently on the right side as compared to the left. Thomas et al. in their study also found scrotal hydrocele to be more common on the right. ${ }^{5}$

Management of Hydrocele: No intervention is necessary unless the hydrocoele reaches a critical size that leads to awkwardness or pain in walking, in which case drainage can be done in general practice settings. Treatment for recurrent hydrocoele includes aspiration followed by sclerotherapy (using phenol, ${ }^{6}$ tetracycline, ${ }^{7}$ or sodium tetradecylsulfate ${ }^{8}$ or hydrocoelectomy. ${ }^{9}$ Hydrocoelectomy, although more invasive and costly, has been shown to have higher success rates, improved outcomes and patient satisfaction as compared with other form of sclerotherapy. ${ }^{10}$

\section{Conclusion}

Right sided hydrocele is more common as compared to left sided hydrocele. This study showed that 60 (54.54\%) patients had Right sided hydrocele as compared to $46(41.81 \%)$ patients who had Left sided hydrocele.

The age group of 31-40 years was the most commonly affected age group affected which consisted of $34.54 \%$ of patients. This was followed closely by age group of 21-30 years, 4150 years and 51-60 years which affected $18.18 \%$ patients each.

\section{References}

1. Simonsen PE, Meyrowitsch DW, Makunde WH, Magnunssen P. Bancroftianfilariasis: The pattern of microfilaraemia and clinical manisfestations in three endemic communities of northeastern Tanzania. Acta Trop. 1995;60:179-87.

2. Sandlow JI, Winfield HN, Goldstein M. Surgery of the scrotum and seminal vesicles. In: Wein AJ, Kavoussi LR, Novick AC, Partin AW, Peters CA, editors. Campbell - Walsh Urology. 9th ed. Philadelphia: Saunders Elsevier; 2007. pp. 1098-127.

3. Nundy S. Difficulties of surgery in the developing world: A personal view. Lancet. 1999;353(suppl. 1):21-3.

4. Okorie CO, Pisters LL, Liu P. Longstanding hydrocele in adult Black Africans: Is preoperative scrotal ultrasound justified?. Niger Med J. 2011;52(3):173176. doi:10.4103/0300-1652.86130

5. Thomas G, Richards FO, Jr, Eigege A, Dakum NK, Azzuwut MP, Sarki J, et al. A pilot program of mass surgery weeks for treatment of hydrocele due to lymphatic filariasis in central Nigeria. Am J Trop Med Hyg. 2009;80:447-51.

6. Savion M, Wolloch Y, Savir A. Phenol sclerotherapy for hydrocele: A study in 55 patients. J Urol. 1989;142:1500-1.

7. Suwan P. Treatment of hydroceles by aspirations and tetracycline instillations. $\mathrm{J}$ Med Assoc Thai. 1994;77:421-5. 
8. Suwan P. Treatment of hydroceles by aspirations and tetracycline instillations. J Med Assoc Thai. 1994;77:421-5.

9. Beiko DT, Kim D, Morales A. Aspiration and sclerotherapy versus hydrocelectomy for treatment of hydroceles. Urology. 2003; 61:708-12.

10. Khaniya S, Agrawal CS, Koirala R, Regmi R, Adhikary S. Comparison of aspirationsclerotherapy with hydrocelectomy in the management of hydrocele: A prospective randomized study. Int J Surg. 2009;7:3925. 